PROGRESS REPORT

\title{
DEVELOPMENT OF ADVANCED IN SITU TECHNIQUES FOR CHEMISTRY MONITORING AND CORROSION MITIGATION IN SCWO ENVIRONMENTS
}

\author{
prepared by \\ Z. Meng, X.Y. Zhou, S.N. Lvov, and D.D. Macdonald \\ Center for Advanced Materials, The Pennsylvania State University \\ 517 Deike Building, University Park, PA 16802
}

\author{
prepared for: \\ Dr. Gerald Goldstein \\ Environmental Management Science Program \\ U. S. Department of Energy \\ 19901 Germantown Road \\ Germantown, MD 20874
}

October 1997 


\section{EXECUTIVE SUMMARY}

This report evaluates the first year's results of our research on the development of advanced electrochemical sensors for use in high subcritical and supercritical aqueous environments. Our work has emphasized the designing of an advanced reference electrode, and the development of high-temperature $\mathrm{pH}$ and redox sensors for characterizing the fundamental properties of supercritical aqueous solutions. Also, electrochemical noise sensors have been designed for characterizing metal/water interactions, including corrosion processes. A test loop has been designed and constructed to meet the expected operation conditions. We have also developed an approach to define a practical $\mathrm{pH}$ scale for use with supercritical aqueous systems and an operational electrochemical thermocell was tested for $\mathrm{pH}$ measurements in $\mathrm{HCl}+\mathrm{NaCl}$ aqueous solutions. The potentials of the thermocell for several $\mathrm{HCl}(\mathrm{aq})$ solutions of different concentrations have been measured over wide ranges of temperature from 25 to $400^{\circ} \mathrm{C}$ and for flow rates from 0.1 to 1.5 $\mathrm{cm} \min ^{-1}$. The corresponding $\mathrm{pH}$ differences (\lrcorner $\left.\mathrm{pH}\right)$ for two $\mathrm{HCl}(\mathrm{aq})$ concentrations in 0.1 $\mathrm{NaCl}(\mathrm{aq})$ solution have been experimentally derived and thermodynamically analyzed. Our first experimental measurements, and subsequent theoretical analysis, clearly demonstrate the viability of $\mathrm{pH}$ measurements in high subcritical and supercritical aqueous solutions with a high accuracy of $=0.02$ to 0.05 units. 


\section{INTRODUCTION}

Super-critical water (SCW) exhibits properties that are used for many applications. One of the important applications of SCW is as a reaction medium in supercritical water oxidation (SCWO) technology, especially for eliminating various military organic wastes. This process offers no emissions with very impressive destruction rates and efficiencies. However, the currently poor knowledge of the fundamental properties of supercritical fluids hinders the efficient application of this process.

Potentiometry is one of the most powerful tools that we have for exploring the thermodynamics, kinetics, and other physico-chemical characteristics of high temperature aqueous solutions. However, only a few accurate measurements apparently have been made in supercritical environments, due to the lack of appropriate electrochemical sensors and reference electrodes. A major barrier for studying many different technologicallysignificant physicochemical processes in aqueous systems at high subcritical and supercritical temperatures is the lack of a reliable and generally applicable method for measuring $\mathrm{pH}$. If $\mathrm{pH}$ could be measured accurately at temperatures above $325^{\circ} \mathrm{C}$, we would significantly increase our knowledge of protolytic phenomena, including acid-base dissociation, hydrolysis, ion-pairing, solubility processes, and their associated standard thermodynamic properties. From a technological viewpoint, this knowledge would greatly aid progress in all of the areas of science and technology noted above.

In previous studies involving precise electrochemical measurements in high temperature aqueous systems up to $300^{\circ} \mathrm{C}$, Macdonald and co-workers [1, 2] and Mesmer and coworkers [3] investigated various aqueous solutions from 0 to $300^{\circ} \mathrm{C}$ using platinumhydrogen $\left[\mathrm{Pt}\left(\mathrm{H}_{2}\right)\right]$ electrodes as both the test and reference electrodes in concentration cells. This technique is very precise, but it suffers from the distinct disadvantage that the system under study must be stable to the presence of hydrogen. Nevertheless, the applicability of the $\mathrm{Pt}\left(\mathrm{H}_{2}\right)$ electrode for sensing hydrogen ion activity in high subcritical and supercritical aqueous solutions was demonstrated by Macdonald et al. [4], 
Hettiarachchi et al. [5], Macdonald et al. [6], Lvov et al. [7], and Ding and Seyfried [8, 9]. This electrode has been recently used to measure Henry's Law constants for $\mathrm{H}_{2}(\mathrm{aq})$ [10] at temperatures up to $450^{\circ} \mathrm{C}$. Another noble metal $\mathrm{Au}\left(\mathrm{H}_{2}\right)$ electrode has also been demonstrated to act as a Nernstian electrode in supercritical aqueous systems [11].

One of the most significant achievements in high temperature potentiometry was the development of the yttria-stabilized zirconia (YSZ) membrane sensor, which was demonstrated to be a primary (Nernstian) $\mathrm{pH}$ electrode that is well-suited for potentiometric measurements in high subcritical and supercritical systems [4-12] at temperatures up to $550^{\circ} \mathrm{C}$ [12]. However, all potentiometric techniques employ a reference electrode and, to date, it has been the accuracy of the reference electrode that has determined the accuracy of the measured potential, and hence the $\mathrm{pH}$. The critical role played by the reference electrode in determining the quality of potentiometric data is well recognized $[9,13,14]$, and it is clear that little progress will be made in potentiometry of high subcritical and supercritical aqueous systems until an accurate reference electrode is devised.

All general and localized corrosion processes, such as general corrosion, pitting attack, and crevice corrosion, result in fluctuations in the free corrosion potential and in anodic and cathodic partial currents. These fluctuations are observed as electrochemical noise that is thought to contain significant information about both the activity and mechanism of attack Electrochemical Noise Spectroscopy (ENS) has been used extensively for monitoring corrosion activity in a variety of systems at ambient temperature, although the sources of the electrochemical noise are still not clearly defined. Some believe that the electrochemical noise is due principally to the formation of hydrogen bubbles, at least in the case of general corrosion, or to the absorption of hydrogen by the first layers of metal beneath the surface of passive film. In the case of localized corrosion, the noise frequently arises from discrete events that can be related to the development of damage. In previous work in this laboratory, Macdonald et al. [15] and Kriksunov and Macdonald [16] developed an ENS system based on a zero resistance ammeter (ZRA) coupled to a band- 
pass-filter/RMS (root-mean-squares) integrated circuit to monitor electrochemical noise on carbon steel and stainless steels in aqueous solutions at temperatures ranging from $200^{\circ} \mathrm{C}$ to $550^{\circ} \mathrm{C}$. These studies demonstrated the viability of ENS for monitoring corrosion phenomena in high subcritical and supercritical aqueous systems, and confirmed the previous\& observed maximal corrosion rate within the neighborhood of the critical temperature $\left(350-400^{\circ} \mathrm{C}\right)$. The studies also demonstrated the (half order) dependence of the noise amplitude, which is considered to be related to the corrosion rate, on the oxygen concentration. These previous studies, upon which the present work is based, has clearly shown that ENS is a potentially valuable method for the in situ monitoring of corrosion rate.

Our objectives in the present work is to concentrate on fundamental studies of the supercritical fluid system as well as on developing new sensor concepts for use in SCWO systems. The precision and reliability of sensoring techniques will be improved, and advanced electrochemical noise monitoring techniques for use in SCWO system will be developed. Several tasks will be fulfilled in this project: (i) Design and construction of a high temperature/high pressure test loop, test reactor, data acquisition system, electrochemical noise monitoring system, and pH probes; (ii) Measurement and analysis of electrochemical noise in high subcritical and supercritical water and aqueous solutions; (iii) Further development of $\mathrm{pH}$ sensors and the development of the supercritical $\mathrm{pH}$ scale, and; (iv) Studies of supercritical aqueous chemistry and electrochemistry using the bench scale reactor at Idaho National Engineering and Environmental Laboratory. This latter task will be carried out in cooperation with Karen Garcia of INEEL, and our goal is to supply rugged $\mathrm{pH}$ sensors and reference electrodes for installation in her prototype SCWO system during the next reporting period.

The research done so far is described in the two following sections. The first section describes the $\mathrm{pH}$ measurements, which were carried out in subcritical and supercritical aqueous solutions using a newly-developed reference electrode in an existing apparatus. 
The second part includes detailed descriptions and designs of the test loop and sensors, which eventually will be employed in our studies at the Pennsylvania State University.

\section{pH MEASUREMENTS IN SUBCRITICAL AND SUPERCRITICAL AQUEOUS SOLUTIONS}

At low temperatures $\left(<100^{\circ} \mathrm{C}\right), \mathrm{pH}$ is determined with reference to a standard (buffer) solution, the $\mathrm{pH}$ of which we assume to be known. Thus, as noted in the IUPAC's Manual on Physical Chemistry Definitions [17], the $\mathrm{pH}$ of the test solution $\mathrm{X}$ is defined as

$p H\left(. K^{5}\right)=p H(S)-\frac{F\left(E_{0}-E_{y}\right)}{2.303 R T}$

for the following galvanic cell

Reference Electrode! $\mathrm{KCl}\left(\mathrm{aq}, \mathrm{m}>3.5 \mathrm{~mol} \mathrm{~kg}^{-1}\right) \|$ Solution $\mathrm{X} \mid \mathrm{Pt} / \mathrm{H}_{2}$,

where $S$ is the $\mathrm{pH}$ of the standard solution, and $E_{S}$ and $E_{x}$ are the potentials measured against the same reference electrode. Thus, as IUPAC recommends, we do not need to know the absolute potential of the reference electrode, but we do require it to be stable and invariant from one test measurement to another at a given temperature and pressure. We also need to have available standard solutions, whose $\mathrm{pH}$ is known a priori. We have adopted a similar approach with the advanced Flow-Through External Pressure-Balanced Reference Electrode (FTEPBRE), which is described in detail elsewhere [ 14]. 


\section{Flow-Through External Pressure-Balanced Reference Electrode}

To achieve high accuracy in potentiometric measurements at high temperatures, a reference electrode should meet the following requirements, which are considerably more stringent than those for ambient conditions:

(1) High resistance to chemical degradation;

(2) Good tolerance to thermal and pressure (mechanical) stress; and

(3) Accurate resolution of measured potentials to $\pm \mathrm{a}$ few $\mathrm{mV}$

The principle we adopted for the reference electrode is a flow-through technique, which can minimize interference from both contaminates (e.g., corrosion products) and from the Soret effect, thereby providing a stable and highly accurate reference potential. As follows from our previous theoretical analysis of the thermal liquid junction potential problem [13], the FTEPBRE, in which the non-isothermal liquid junction is maintained accurately at a well-defined composition, was considered to be an appropriate way to solve the problem of performing accurate potentiometric measurements in high temperature, high pressure aqueous systems.

Briefly, the FTEPBRE employs techniques to minimize the effect of thermal diffusion on the reference potential, with the isothermal liquid junction potential being estimated from solution theory (see below). The unique feature of the FTEPBRE is that the reference solution flows through the electrode, so that the species concentrations across the thermal liquid junction are maintained constant [14]. Thus, any tendency for thermal diffusion to occur is eliminated at the given temperature and pressure, and hence the electrode may be maintained in the stable Soret initial state. 


\section{High Temperature pH Thermocell}

The silver-silver chloride/platinum-hydrogen, non-isothermal thermocell [14]

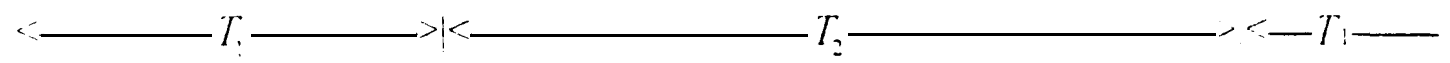

$\mathrm{Cu}|\mathrm{Ag}| \mathrm{AgCl} ! 0.1 \mathrm{~m} \mathrm{NaCl}(\mathrm{aq}) \| 0.1 \mathrm{~m} \mathrm{NaCl}(\mathrm{aq})+\mathrm{HCl}(\mathrm{aq})\left|\mathrm{H}_{2}(\mathrm{Pt})\right| \mathrm{Pt} \ldots \mathrm{Pt} \mid \mathrm{Cu}$ (II)

was employed for $\mathrm{pH}$ measurements in $\mathrm{HCl}(\mathrm{aq})+\mathrm{NaCl}(\mathrm{aq})$ solutions over wide ranges of temperature from 25 to $400^{\circ} \mathrm{C}$ and pressure between 187 and 253 bar. This cell exhibits great stability of the measured potential (within $\pm 2 \mathrm{mV}$ ) for long periods of time ranging from a few hours up to a few days. An example of the voltage stability of the thermocell as measured by flow-through experimental at $200^{\circ} \mathrm{C}$ and 250 bar is presented in Figure 1.

A significant issue in high temperature $\mathrm{pH}$ measurements is the diffusion or isothermal liquid junction potential (ILJP). It is common practice [17,18] in subcritical work to suppress the ILJP by employing a high concentration $(>3.5 \mathrm{~m})$ of $\mathrm{KCl}$. However, this is only effective if the test solution is dilute. This is not easily accomplished at supercritical temperatures, because of a possible phase separation of highly concentrated solutions that might be employed in the reference electrode internal compartment. For example, in the case of $\mathrm{NaCl}$, the highest concentration that one can have is about $0.1 \mathrm{~m}$ at temperatures up to $450^{\circ} \mathrm{C}$ and pressures up to 500 bar without having phase separation [19]. However, this problem is mitigated by the fact that the transport numbers for $\mathrm{Na}$ and $\mathrm{Cl}^{-}$rapidly converge to the same value as the temperature exceeds $300^{\circ} \mathrm{C}$ and transitions across the critical value [20]. Accordingly, $\mathrm{NaCl}$ solution is of great interest for use as the reference electrode internal solution at elevated temperatures $\left(300-450^{\circ} \mathrm{C}\right)$, because: $(1)$ it emulates $\mathrm{KC} 1$ in its transport numbers, and (2) the dissociation constant of $\mathrm{NaCl}(\mathrm{aq})$ is well known over wide ranges of temperature and pressure [20]. Note that there are no reliable conductivity or dissociation constant data for $\mathrm{KCl}(\mathrm{aq})$ solutions at the temperatures of 


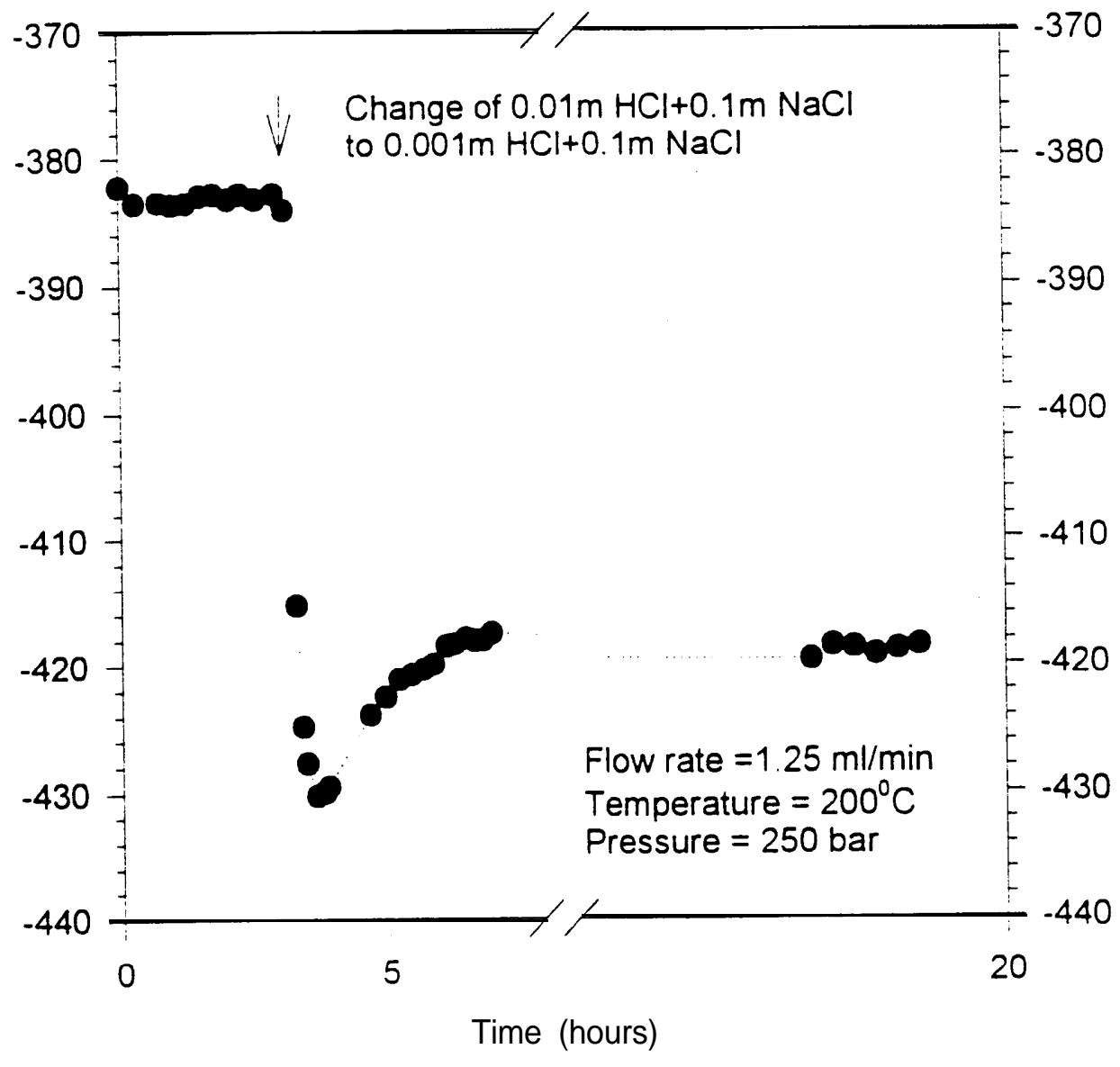

Figure 1. Voltage stability of Thermocell (I) as measured by flow-through experiments at $200^{\circ} \mathrm{C}$ and 250 bar. 
interest, but the requisite data are available for $\mathrm{NaCl}(\mathrm{aq})$ solutions. Accordingly, for this latter system, the residual ILJP can be theoretically estimated, as is the common practice for high-accuracy work at ambient temperature, using the full expression for the liquid junction potential as

$$
E_{n}=-\frac{R T}{F} \sum_{i} \int \frac{t_{1}}{z_{i}} d \ln a_{i}
$$

where the summation is taken over all ions (activitya: and valence $z$ ) in the junction with the integral being evaluated over the dimension of the junction, rather than by using the Henderson equation, which assumes ideality. We have calculated the ILJP for the junction of Thermocell (II), where $0.1 \mathrm{~m} \mathrm{NaCl}$ (aq) was used as the reference solution and $\mathrm{HCl}(\mathrm{aq})$ (with concentrations less then $0.01 \mathrm{~m}$ ) mixed with $0.1 \mathrm{~m} \mathrm{NaCl}(\mathrm{aq})$ were employed as the test solutions. It was found that the ILJP is of the same order as that at ambient temperature, because the increase in $R T F$ with increasing temperature is compensated for by the decrease in the summed quantities (note that for a $1: 1$ electrolyte $z_{i}=1, z_{z}=-1$ and $t_{1} \rightarrow t_{2}$ and $\quad a_{1} \rightarrow a_{2}$ as the concentration decreases and as the temperature increases). Our calculations show that the values of $E_{D}$ for Thermocell (II) range from 1 to $3 \mathrm{mV}$. While not large, they are significant, and the accurate determination of $\mathrm{pH}$ requires correction of the reference electrode potential for this effect using Eqn. (2).

Dilute $\mathrm{HCl}(\mathrm{aq})$ mixed with $0.1 \mathrm{~m} \mathrm{NaCl}(\mathrm{aq})$ solutions were chosen for our first experimental studies because: ( 1 ) the dissociation constants data are available for temperatures up to at least $400^{\circ} \mathrm{C}$; and (2) they are sufficiently dilute that activity coefficients can be estimated using extended Debye-Huckel theory. 


\section{Results of Measurements and Discussion}

We have measured the potentials of Thermocell (II), $E^{i i t}$, for two $\mathrm{HCl}(\mathrm{aq})$ solutions [0.01m and $0.001 \mathrm{~m}$ mixed with $0.1 \mathrm{~m} \mathrm{NaCl}(\mathrm{aq})]$. Because the thermodynamics of these solutions are well known over the entire temperature range of interest, one of them was assumed to be the test solution, $X$, and another one the standard solution, $S$. The measured $\mathrm{pH}$ difference is then expressed as

$$
\Delta p H_{r,}=[p H(X)-p H(S)]_{\ldots,}=\frac{F \Delta E}{2.303 R T}-\left[E_{D}(S)-E_{.}\left(X^{\prime}\right)\right]
$$

The values $E_{D}(S)(i=S$ or $X)$ in Eqn. (3) are the isothermal liquid junction potentials between the standard and test solutions of Thermocell (II) at temperature $T_{2}$, which can be theoretically calculated [by Eqn.(2)] if we know the equivalent conductances and concentrations of the species of both standard and test solutions.

The measured $\Delta E^{(I)}$ values can be compared to the theoretical calculations. Accordingly, these measurements can be used to check the measured potentials quantitatively and by this means to confirm the accuracy of the FTEPBRE. The calculations of $\mathcal{N}$ " values were carried out by

$$
\Delta E^{(I I)}=\frac{R T_{2}}{F} \ln \frac{m_{H^{*}}(S) \gamma_{H^{*}}(S)}{m_{H^{-}}(X) \gamma_{H^{-}}(Y)}+\left[E_{D}(S)-E_{D}(X)\right]
$$

where $\mathrm{m}_{\text {н. }}(S)$ and $m_{\text {H- }}(X)$ are the concentrations of $\mathrm{H}(\mathrm{aq})$ ion in the standard and test solutions, respectively, and $\gamma_{H-}(S)$ and $\gamma_{H-}(X)$ are the activity coefficients of $\mathrm{H}(\mathrm{aq})$. 
For calculating $m_{H-}(S)$ and $m_{H-}(X)$, we solved the speciation problem for each solution given the total (stoichiometric) composition, temperature, and density. In doing so, we considered the following dissociation equilibria in describing the system:

$\mathrm{H}_{2} \mathrm{O}(\mathrm{l}) \leftrightarrow \mathrm{H}^{*}(\mathrm{aq})-\mathrm{OH}^{*}(\mathrm{aq})$,

$\mathrm{HCl}^{\prime \prime}(\mathrm{aq}) \leftrightarrow \mathrm{H}^{-}(\mathrm{aq})+\mathrm{Cl}^{-}(\mathrm{aq})$

$\mathrm{NaCl}^{\prime \prime}(\mathrm{aq}) \leftrightarrow \mathrm{Na}(\mathrm{aq})-\mathrm{Cl}-(\mathrm{aq})$,

$\mathrm{NaOH}^{\prime \prime}(\mathrm{aq}) \leftrightarrow \mathrm{Na}^{-}(\mathrm{aq})-\mathrm{OH}-(\mathrm{aq})$

together with the electroneutrality and mass balance constraints. The activity coefficients of the ions,$y_{:}$, were calculated using the second-order approximation of the DebyeHuckel theory.

It was found that theoretically-calculated values [by Eqn.(4)] of $\Delta E^{(/ I)}$ agree with the experimental data to within $\pm 1-2 \mathrm{mV}$ and this comparison is presented in Figure 2. We emphasize, however, that the difference between the measured and calculated potentials should not be attributed to the reference electrode alone, because Eqn. (4) contains parameters (e. g. the activity coefficients and isothermal liquid junction potentials) whose uncertainties could easily account for the measured differences. The results of our measurements demonstrate the viability of the high temperature (subcritical and supercritical) $\mathrm{pH}$ measurements and we believe that the $\mathrm{pH}$ values can be measured with a high accuracy within $=0.02$ to 0.05 logarithmic units. 


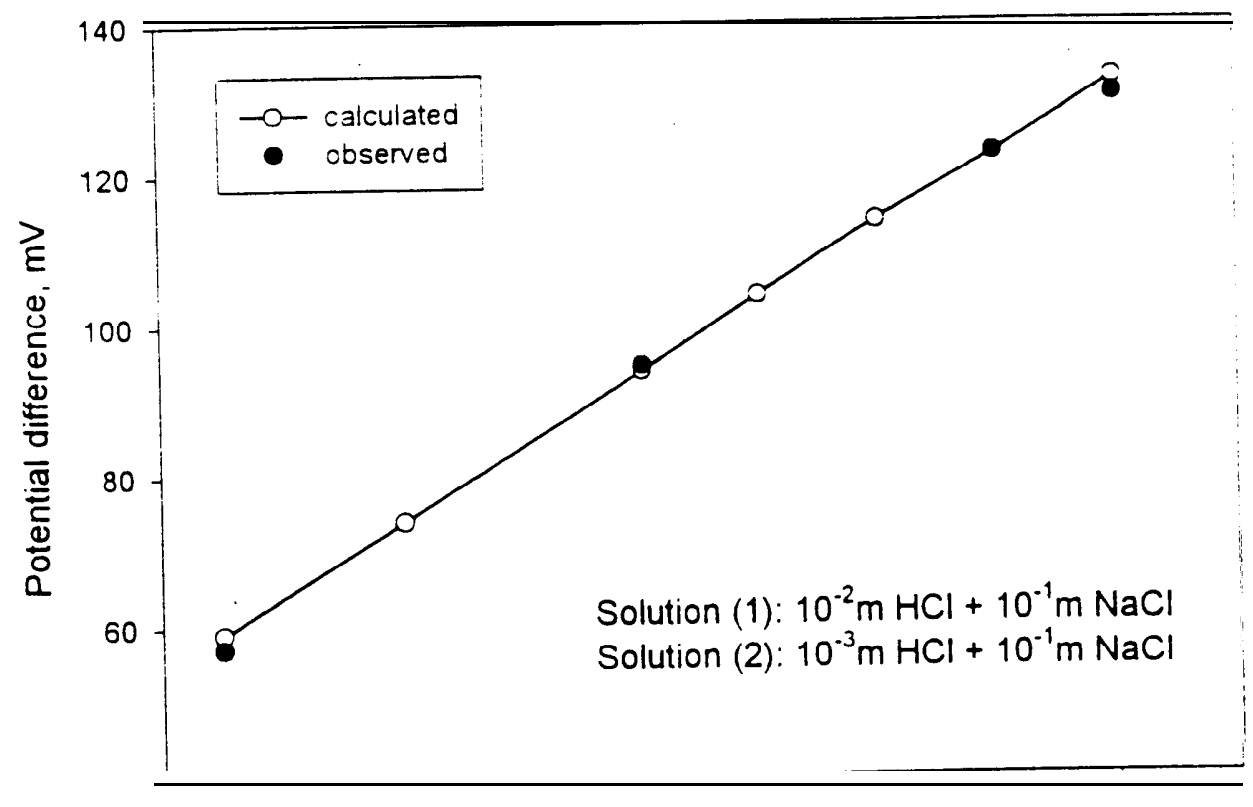

Temperature, ${ }^{\circ} \mathrm{C}$

Figure 2. Comparison of the calculated and observed $\Delta E^{(I)}$. values over a wide range of temperature from 25 to $400^{\circ} \mathrm{C}$ 


\section{DESIGN OF AUTOCLAVE CIRCULATION LOOP AND VARIOUS IN-SITU SENSORS}

\section{Design of Reaction Cell and Circulation Loop}

A new cell has been designed to serve as the measurement vessel of our circulation loop. Titanium alloy Grade 5 was chosen as the construction material for the reaction cell, because of its suitable corrosion resistance under the severe conditions of operation and because its high mechanical strength at high temperatures. Two schematics of the reaction cell are shown in Figures 3 and 4. The reference electrode, the redox sensor, the yttria stabilized zirconia (YSZ) pH sensor, and the electrochemical noise sensor will be installed into the four penetrations shown in Figure 5 for in-situ monitoring and measurement. The designs of these electrodes will be covered later in this section.

The once-through flow loop, shown schematically in Figure 6, will be used for our experiments. Two High Pressure Liquid Chromatography (HPLC) pumps will be employed, one for pumping in of the reaction solution through the loop and the other for pumping in of the reference solution through the reference electrode. A back pressure regulator will be used to maintain the pressure in the loop at 400 bar. The pressure will be monitored by a standard pressure gauge and also electronically via a pressure transducer connected to the data acquisition system. The solution will be preheated to $\sim 400^{\circ} \mathrm{C}$ and then heated quickly to $500^{\circ} \mathrm{C}$ by high efficiency heating bands wrapped around the measurement cell. Once through the measurement cell, the test solution will be cooled and finally sent to the spent solution container. 


\section{Design of Various in Situ Sensors}

\section{$\underline{\text { YSZ pH Sensor }}$}

Design of the YSZ pH sensor is shown in Figure 7. The ceramic membrane is a $1 / 4$ inch yttria stabilized zirconia tube $\left(9 \mathrm{wt} \% \mathrm{Y}_{2} \mathrm{O}_{3}\right)$. In order to improve the contact between membrane and internal $\mathrm{Hg} / \mathrm{HgO}$ paste, as well as to remove any impurities attached to the outer surface, the tip of the tube (about $5 \mathrm{~cm}$ ) is preconditioned inside out with boiling hydrofluoric acid for ten minutes. About $0.6 \mathrm{~cm}$ of the tube is then filled with $\mathrm{Hg} / \mathrm{HgO}$ paste (1:1 volume ratio of $\mathrm{HgO}$ and $\mathrm{Hg}$ pestled into a paste). The tip of the Pt wire used to provide electrical contact is coiled to improve the contact and is immersed in the $\mathrm{Hg} / \mathrm{HgO}$ paste, while the rest of the wire is insulated by shrinkable Teflon. The tube is then filled with ceramic cement and sintered at $650^{\circ} \mathrm{C}$ for 5 hours. Finally the YSZ tube is sealed with J.B. Weld epoxy which also provides mechanical support for the CONAX compression fitting.

\section{$\underline{\text { Redox Sensor }}$}

A schematic of the redox sensor is shown in Figure 8. The electrode is a Pt wire, with the tip that is in contact with the high temperature environment coiled and platinized in a hexachloroplatinic acid solution to form a "Pt-black" film. The "Pt-black" increases the contact surface area between the electrode and the test solution, and improves the sensitivity of the sensor. The rest of the Pt wire is coated with zirconia via electrophoretic deposition, and is then covered with a shrinkable PTFE tube in the low temperature region or with a thin alumina tube in the high temperature region. A 1/4 inch NPT CONAX fitting is used to seal the electrode. 


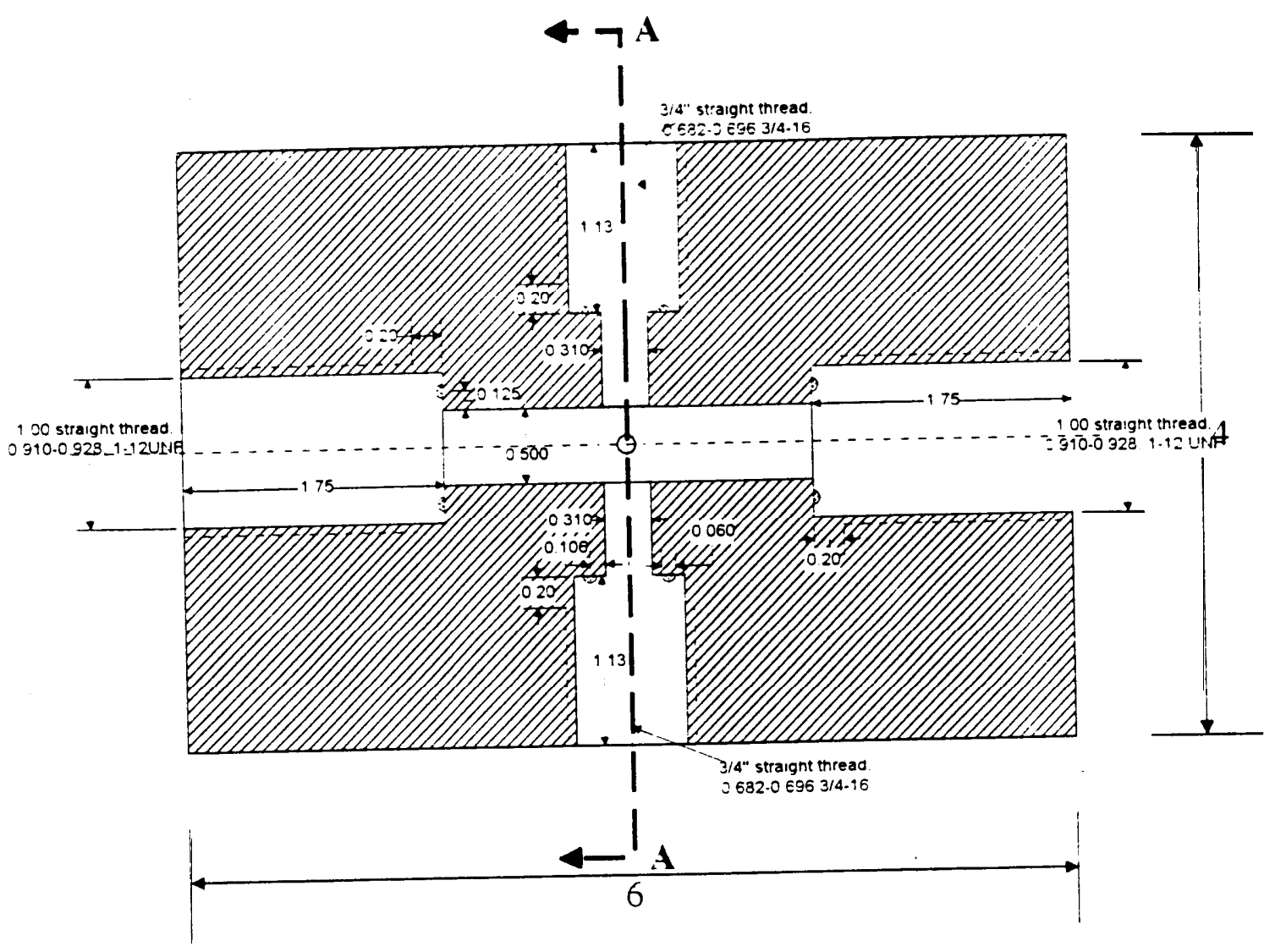

Figure 3. Schematic of the measurement cell. 


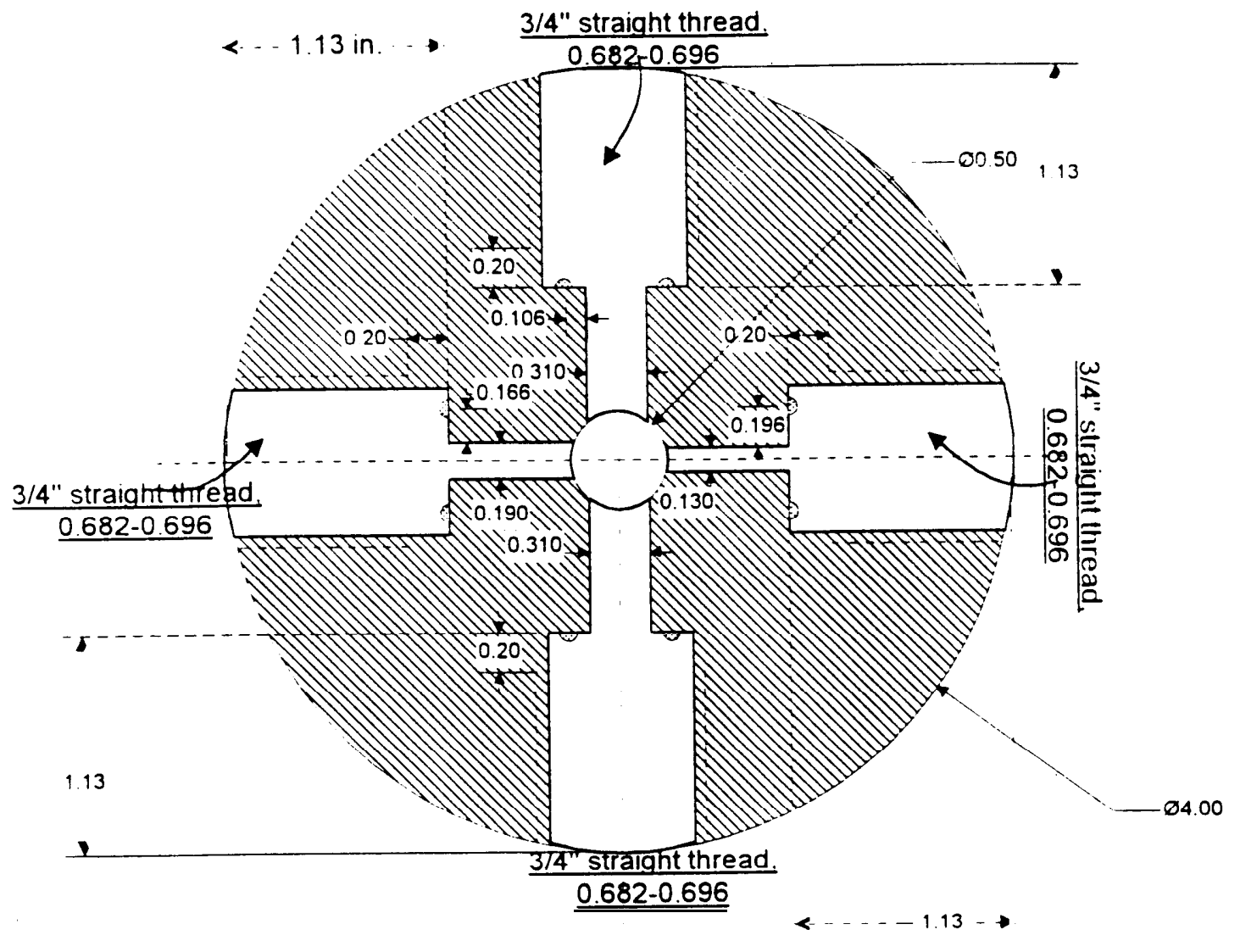

Figure 4. Section AA of the measurement cell (as in Figure 3). 


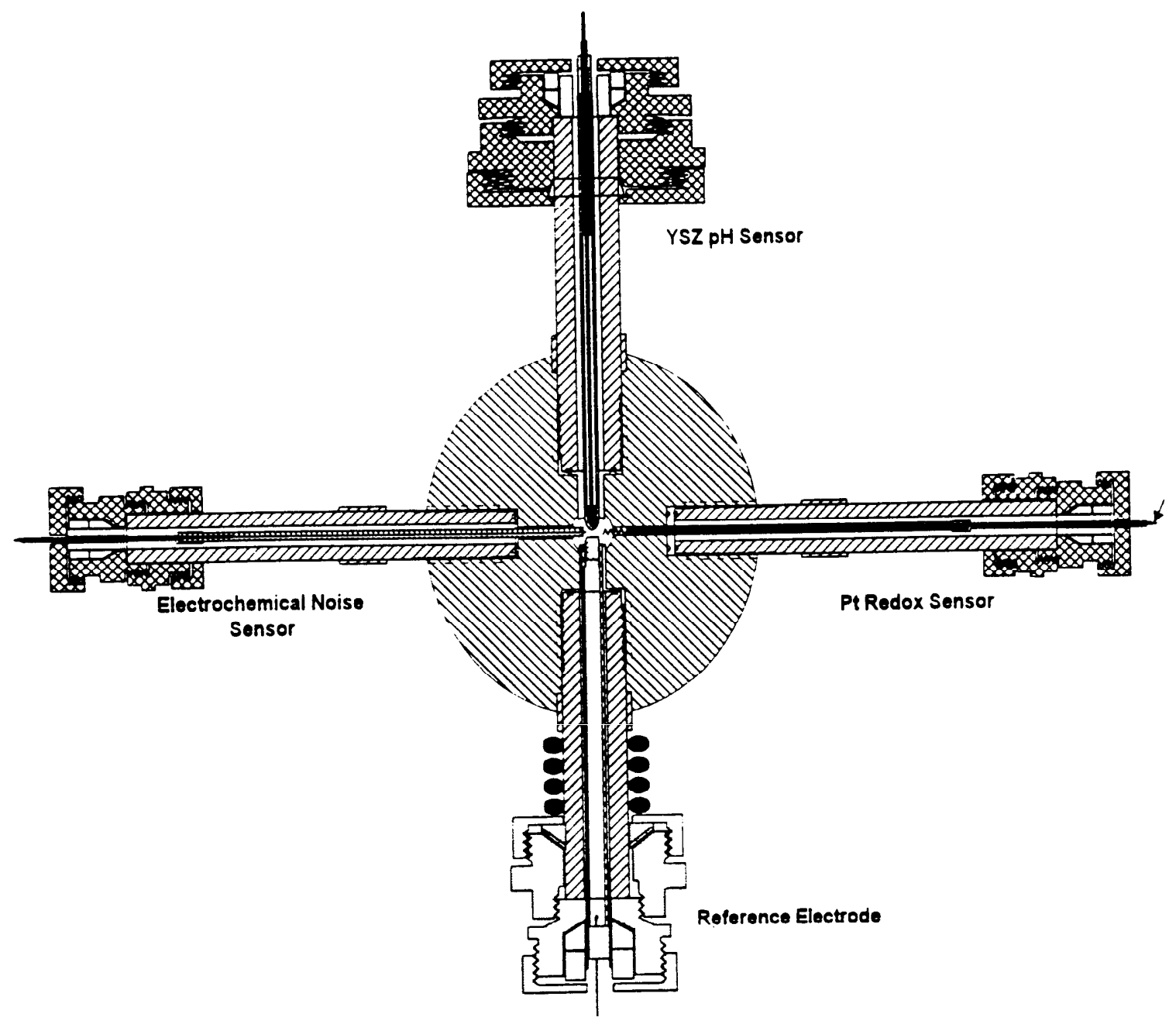

Figure 5. Section AA of the measurement cell showing locations of electrodes. 


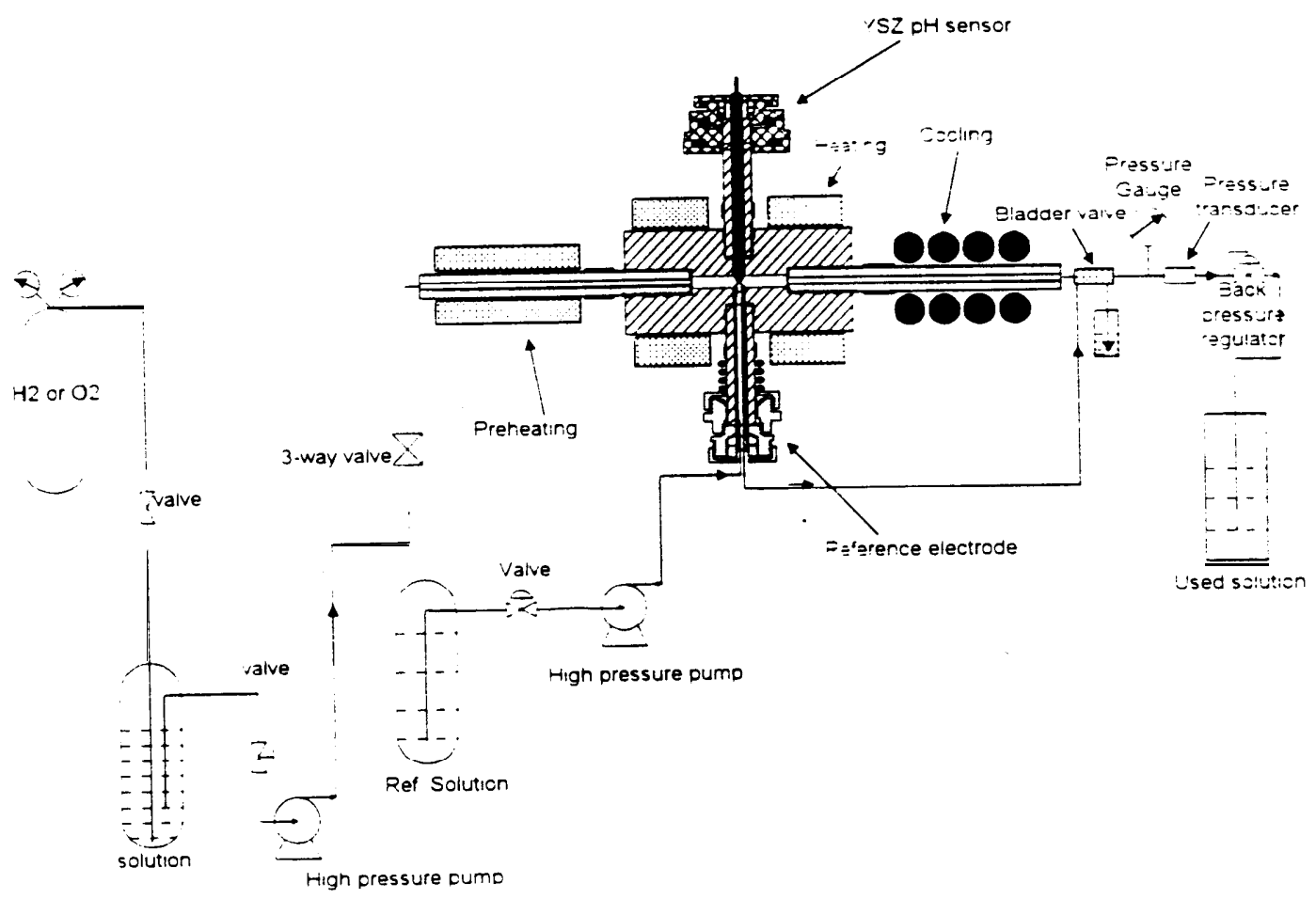

Figure 6. Schematic of the once-through circulation loop. 


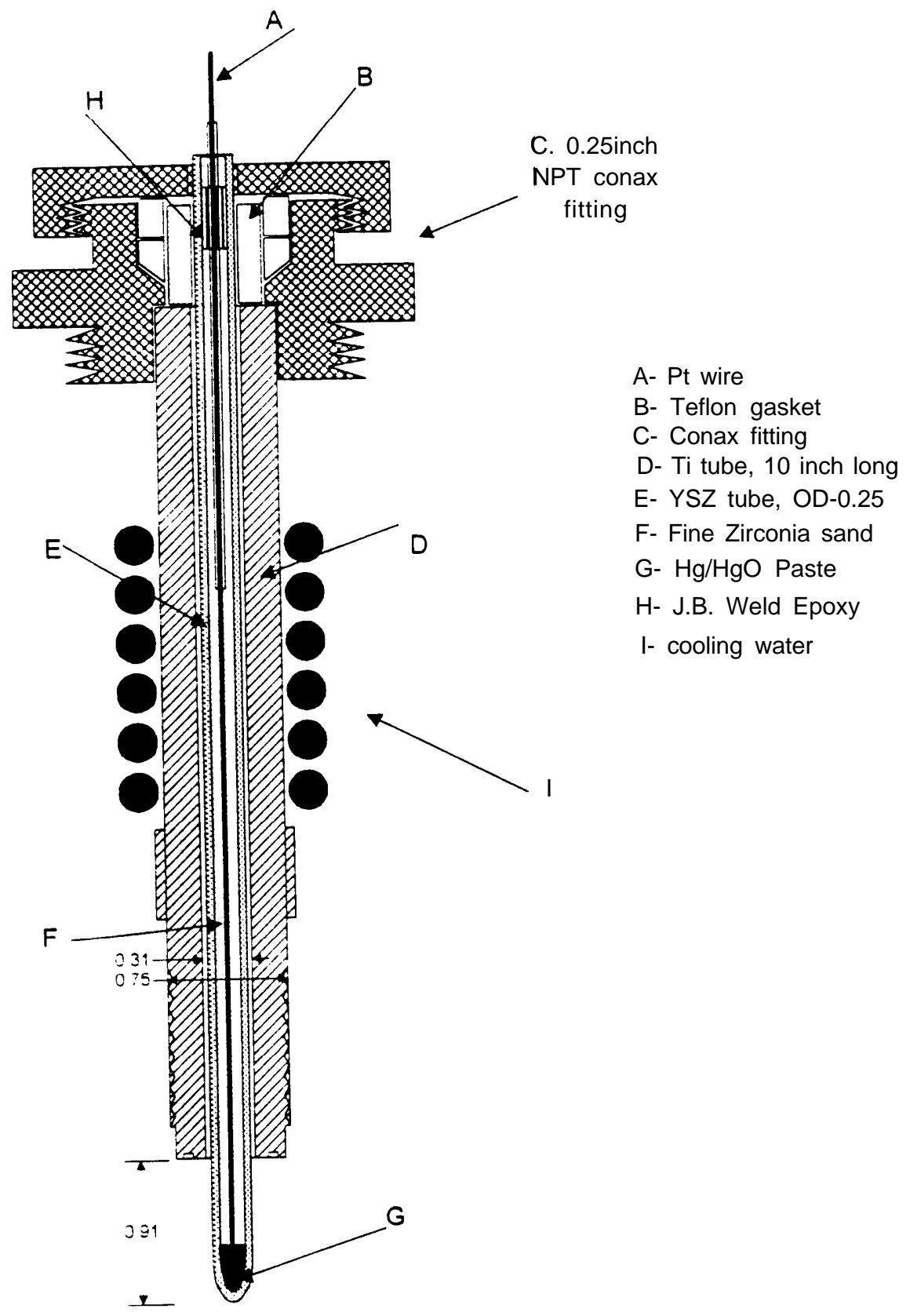

Figure 7. Diagram of the YSZ $\mathrm{pH}$ sensor. 
Flow Through External Pressure Balanced Reference Electrode (FTEPBRE)

An accurate reference electrode that can be used to place a measured potential on the SHE scale is very critical to the accurate measurement of $\mathrm{pH}$ in supercritical systems. A FTEPBRE, of the type described earlier in this report and shown in Figure 9, will be used in this work. This new design keeps a constant flow of reference solution with a known concentration (usually $0.1 \mathrm{~m} \mathrm{NaCl}$ ) inside the tube, so that the species concentrations across the thermal liquid junction are maintained constant. Thus, the electrode operates in the accurately-known and reproducible Soret initial state.

The reference electrode consists of a 1/4 inch oxidized $\mathrm{Zr}$ tube, two thin Ti tubes as inlet and outlet for the reference solution, a $\mathrm{Ag} / \mathrm{AgCl}$ wire electrode, and a metal plug at the tip of the $\mathrm{Zr}$ tube. The reference solution from the outlet of the reference electrode discharges to the bladder valve as shown in Figure 10, thereby, accurately maintaining the pressure in the reference electrode at the same value of the loop and eliminating a second electrolytic conduction path between the reference electrode and the loop. The small crevice between the threads of the metal plug and the $\mathrm{Zr}$ tube allows for electrolytic contact between the reference electrode and test solution, and is sufficiently small to avoid significant contamination of the reference solution because of solutions transfer. The pressure seal is also provided by a NPT CONAX fitting.

\section{Electrochemical Noise Sensor}

Electrochemical noise measurements will be employed to monitor corrosion processes that occur on metallic materials exposed to super critical water (SCW) $[15,16]$. A schematic of the electrochemical noise sensor is shown in Figure 11. It consists of two identical wires as working electrodes and one Pt wire as reference electrode. A thin alumina tube with three holes is used to hold the three wires in a constant geometrical configuration. Other than the tips in contact with high temperature test solution, the wires are insulated by heat shrinkable Teflon or ceramic paste to prevent interference with the 


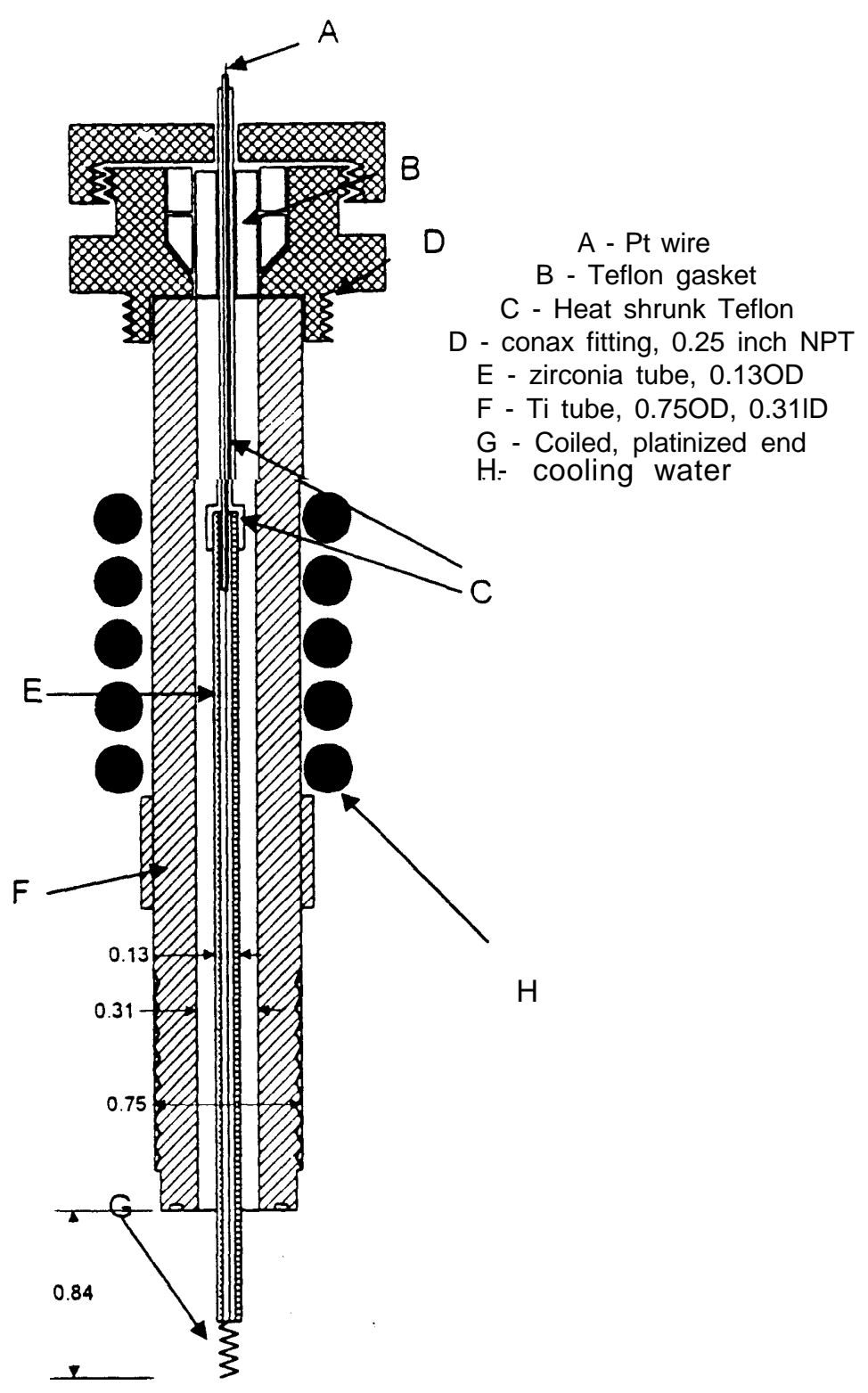

Figure 8. Schematic of the Redox Sensor. 


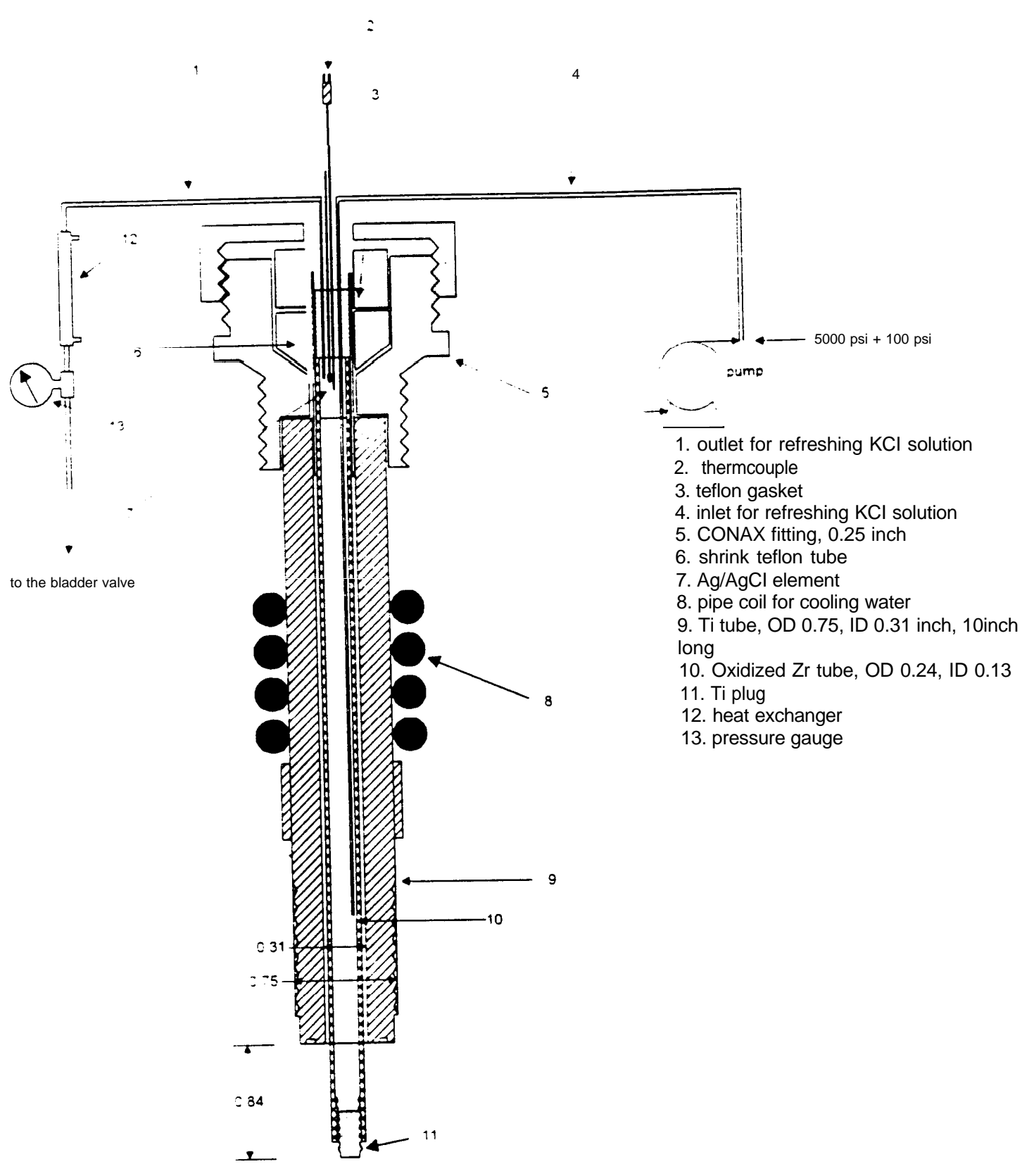

Figure 9. Schematic of the Flow Through External Pressure Balanced Reference Electrode (FTEPBRE). 


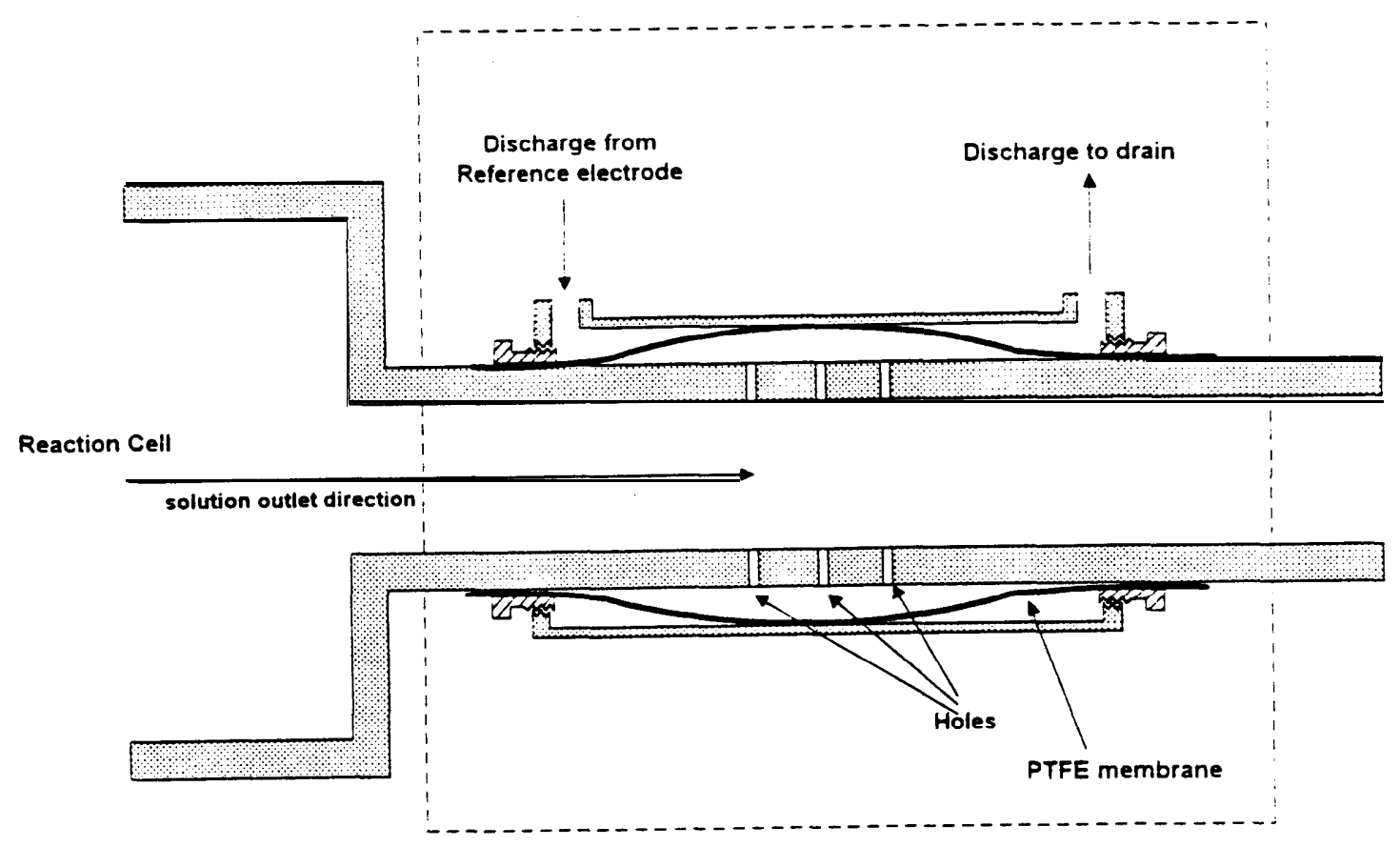

Bladder Valve

Figure 10. Schematic of the bladder valve. 
measurements. The sensor is then sealed by shrinkable Teflon and pressure sealed by a 1/4 inch NPT CONAX fitting, The current fluctuations between the two identical electrodes in test solution can be measured by connecting the two electrodes to a zero-impedance ammeter $[15,16]$. The voltage fluctuations will be recorded by a high impedance voltmeter between one of the working electrodes and the Pt reference electrode. The electric circuit for electrochemical noise analysis (ENA) and the data acquisition system are schematically shown in Figure 12. The reaction cell and extension tubes have been acquired. Assembly of the reaction cell and construction of the circulation loop and sensors are under the way. 


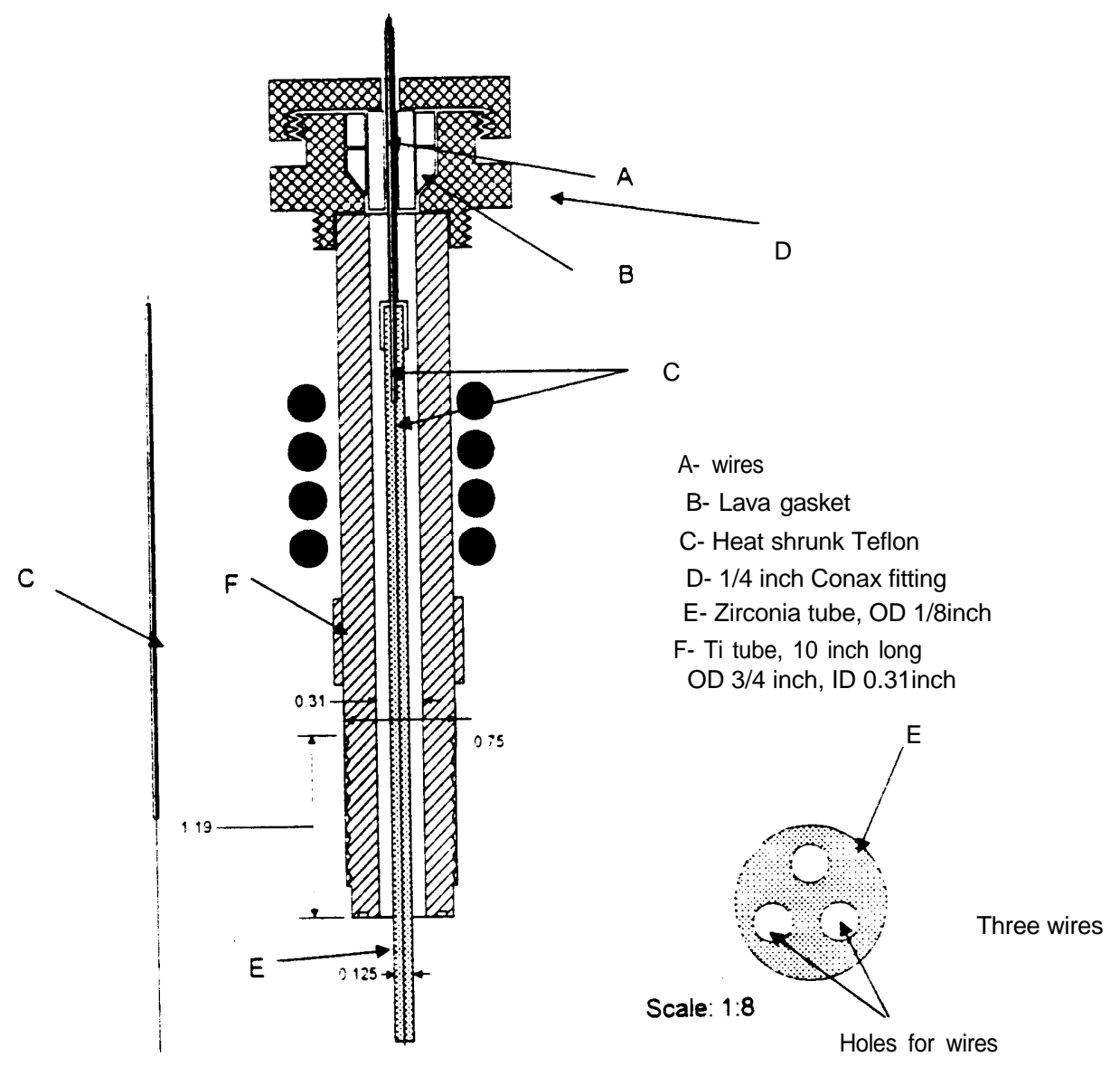

Figure 11. Schematic of Electrochemical Noise Sensor. 


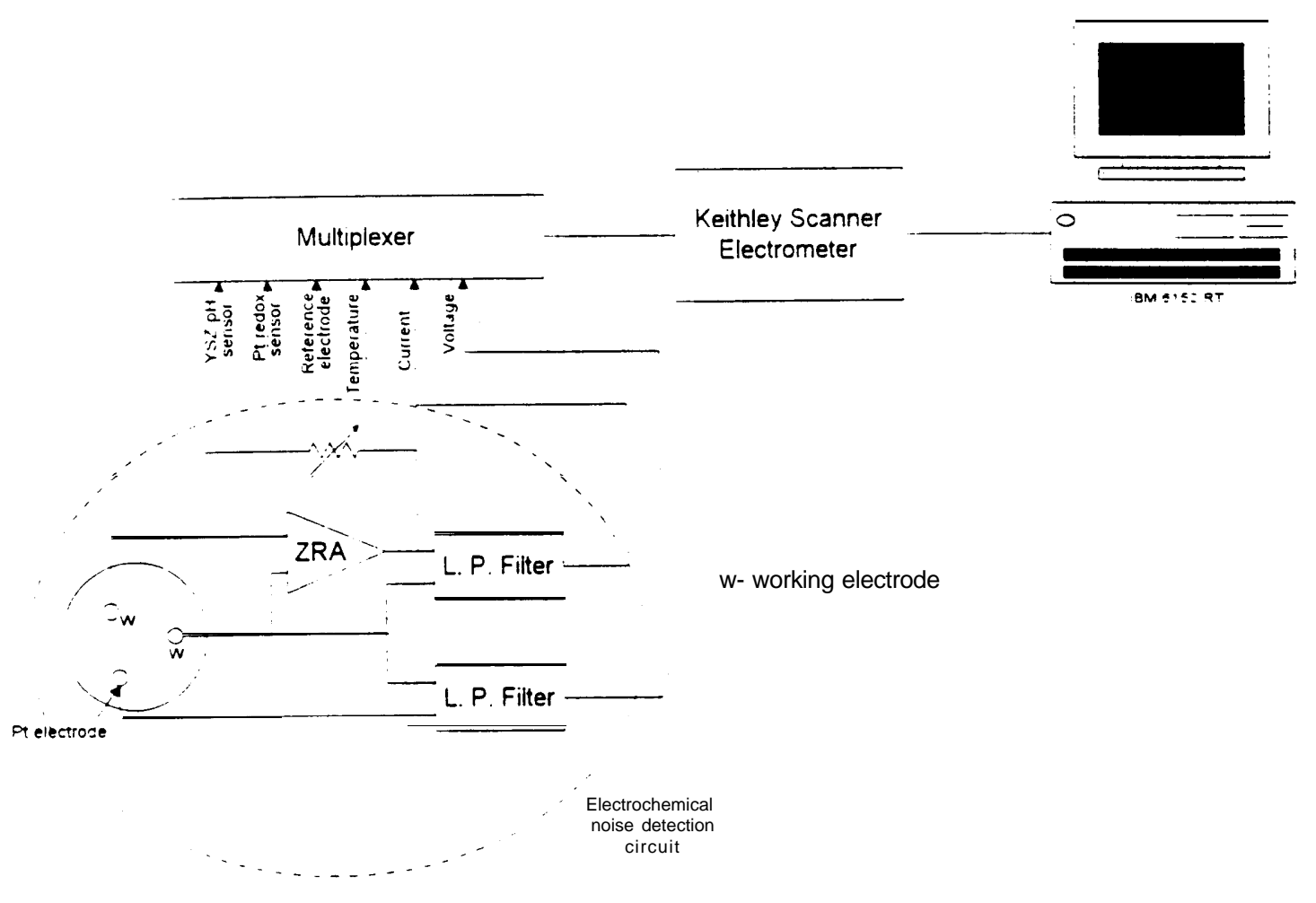

Figure 12. Schematic of electric circuit of ENA. 


\section{SUMMARY AND CONCLUSIONS}

A reaction cell made of titanium Grade 5 material has been designed and constructed on the basis of the expected operational conditions of our system. A test loop has also been designed for the proposed measurements and is now being constructed. YSZ pH sensors, Pt redox sensors, a Flow-Through External Pressure-Balanced Reference Electrode (FTEPBRE), and an electrochemical noise sensor are now being developed for in situ monitoring. The electrochemical noise analyzer will be used for monitoring corrosion activity at temperatures above the critical point of water.

The FTEPBRE has been used for potentiometric measurements in high temperature (up to $400^{\circ} \mathrm{C}$ ) and high pressure ( 300 bar) aqueous solutions. Because the electrolyte concentration profile in the reference electrode is maintained constant, the uncertainty in the thermal liquid junction potential (TLJP) is eliminated at any temperature and pressure. A practical electrochemical thermocell, consisting of a silver-silver chloride FTEPBRE and a flow through platinum-hydrogen $\mathrm{pH}$ sensor, was employed to measure the potentials for two $\mathrm{HCl}(\mathrm{aq})$ solutions $[0.01 \mathrm{~m}$ and $0.001 \mathrm{~m}$ mixed with $0.1 \mathrm{~m} \mathrm{NaCl}(\mathrm{aq})]$. It was found the measured potential difference of the two solutions agree with the theoretically-calculated values to within $\_1-2 \mathrm{mV}$. This result further demonstrates the viability of high temperature (subcritical and supercritical) $\mathrm{pH}$ measurements, and $\mathrm{pH}$ values that are accurate to within $=0.02 \sim 0.05$ units can be measured at temperatures up to $400^{\circ} \mathrm{C}$ by using our new FTEPBRE design.

Finally, we are now constructing a pH sensor and reference electrode that will be delivered to Karen Garcia at INEEL. These electrodes will be installed in INEEL's supercritical water oxidation (SCWO) test system in order to gain field experience with this new monitoring technology. 


\section{REFERENCES}

1. D.D. Macdonald, P. Butler, and D. Owen, Phys. Chem., 77. 2474 (1973).

2. D.D. Macdonald, P. Butler, and D. Owen, Can. J. Chem., 51. 2590 ( 1973).

3. R.E. Mesmer, D.A. Palmer, and D.J. Wesolowski, In 'Physical Chemistry of Aqueous Systems", ed. by H. J. White et al., Begell House, 1995, p. 423-431.

4. D.D. Macdonald, S. Hettiarachchi, and S.J. Lenhart, J. Solut. Chem., 17, 719 (1988).

5. S. Hettiarachchi, K. Makela, H. Song, and D.D. Macdonald, J. Electrochem. Soc., 139. L3 (1992).

6. D.D. Macdonald, S. Hettiarachchi, H. Song, K. Makela, R. Emerson, and M. Haim, J. Solut. Chem., 21. 849 (1992).

7. S.N. Lvov, G. Perboni, and M. Broglia, In "Physical Chemistry of Aqueous Systems", ed. by H. J. White et al., Begell House, 1995, p. 441-448.

8. K. Ding and W. E. Seyfried, Geochim. Cosmochim. Acta, 59. 4769 (1995).

9. K. Ding and W. E. Seyfried, Science, 272, 1634 (1996).

10. K. Eklund, S.N. Lvov, and D.D. Macdonald, J. Electroanal. Chem, (1997) (in press).

11. K. Ding and W. E. Seyfried, J. Solut. Chem., 25, 421 (1996).

12. L. Kriksunov and D.D. Macdonald, (1998) (in preparation)

13. S.N. Lvov and D.D. Macdonald, J. Electroanal. Chem. 403. 25 (1996).

14. S.N. Lvov, H. Gao, and D.D. Macdonald, J. Electroanal. Chem. (1997) (in press).

15. D.D. Macdonald, Chun Liu, and Michael P. Manahan, Sr., American Society for Testing and Materials, 247-265 (1996).

16. L. Kriksunov and D.D. Macdonald, J. Electrochem. Soc., 142. 4069 (1995).

17. IUPAC, Quantities, Units and Symbols in Physical Chemistry Prepared by Ian Mills et al., Blackwell Science, Oxford, 1993, p.60-62.

18. A. K. Covington, Bates R.G., and Durst R.A., Pure Appl. Chem., 57, 531(1985).

19. K. S. Pitzer, R. T. Pabalan, Geochim. Cosmochim. Acta, 50, 1445 (1986).

20. G. H. Zimmerman, M.S. Gruszkiewicz, and R.H. Wood, J. Phys. Chem., 92. 11612 (1995). 